\title{
La Batalla de Cachirí (1816). Representaciones históricas y monumentales sobre la derrota militar de Custodio García Rovira*
}

\begin{abstract}
Resumen
Las representaciones históricas sobre la caída de la federación neogranadina y el restablecimiento del régimen virreinal están asociadas con el accionar militar de Custodio García Rovira, especialmente la derrota de la Unión en la Batalla de Cachirí (febrero 1816). Desde el contraste de diferentes versiones históricas y el análisis del discurso sobre un hecho militar, el artículo compara las memorias de los protagonistas de la Campaña Libertadora con los manuales del centenario, los relatos del bicentenario y la tradición oral, concluyendo que cada versión valida la explicación del vencedor y hace revisionismos históricos que justifican los desaciertos del mártir vencido.
\end{abstract}

Palabras clave: Colombia, Nueva Granada, Historia, Guerra, Independencia, Monumento histórico.

Referencia para citar este artículo: PÉREZ PINZÓN, Luis Rubén (2017). "La Batalla de Cachirí (1816). Representaciones históricas y monumentales sobre la derrota militar de Custodio García Rovira". En Anuario de Historia Regional y de las Fronteras. 22 (1). 71-87.

Fecha de recepción: 22/03/2016

Fecha de aceptación: 16/06/2016

Luis Rubén Pérez Pinzón: Profesor de la Universidad Industrial de Santander. Miembro del grupo de investigación: Dinámicas Sectoriales-Unab. Correo electrónico: lperez14@unab.edu.co.

\footnotetext{
* Texto elaborado en el marco del proyecto Empresarismo y prácticas ciudadanas de los inmigrantes europeos en Colombia. Representaciones de los empresarios extranjeros a través de la literatura económica sobre Santander durante el siglo XIX, 2015-2016. Participaron en las reflexiones y exploraciones asociadas con la construcción del artículo los investigadores en formación del curso en Fuentes Históricas (VIII semestre) del Pregrado en Historia y Archivística (II, 2015) de la Universidad Industrial de Santander: Alvarado Casadiego Carlos Augusto, Álvarez Jaimes Zaira Lucia, Bonilla Ayala Juan Sebastián, Capacho García Carlos Javier, Carreño Gómez Paula Jemima, Lancheros Lozano Liliana Paola, Mariño Moreno Yurley, Pinzón González Ismael Enrique, Prada Solano Raúl Mauricio, Reyes Pérez Edson Rodolfo, Ríos Lozano Sebastián, Rueda Orejarena Fabio Alberto, Sanabria Sanabria Frank Omar, Solano Acevedo Jonathan, Suarez Rodríguez Paola Andrea y Torres Guiza Johan Sebastián.
} 


\title{
The Battle of Cachirí (1816). Historical and Monumental Representations about the Custodio García Rovira Military Defeat
}

\begin{abstract}
Historical representations about the fall of the neogranadina federation and the reinstatement of the vice-royal regime are associated with the Custodio Garcia Rovira military actions, especially the defeat of the Union at the Battle of Cachiri (February 1816). Since the contrast of different historical versions and the analysis of a discourse about a military, fact, the article compares the memories of the main character of the Campaign of liberation with the centenary handbooks, the stories of the bicentennial and the oral tradition, concluding that each version validates the victor's explanation and it makes historical revisionisms that justify the mistakes of the defeated martyr.
\end{abstract}

Keywords: Colombia, New Granada, History, War, Independence, Historical Monument.

\section{A Batalha de Cachirí (1816). Representacoes históricas e monumentais sobre a derrota militar de Custodio García Roviria}

\section{Resumo}

As representações históricas sobre a queda da federação neograndina e o restabelecimento dos regimes de vice-reinado estão associados com o acionar militar de Custodio García Rovira, especialmente a derrota da Uniao na Batalha de Cachirí (fevereiro de 1816). A partir do contraste entre diferentes versões históricas e a analise do discurso sobre um feito militar, o artigo compara as memorias dos protagonistas da Campanha Libertadora com os manuais do centenário, os relatos do bicentenário e a tradição oral, concluindo que cada versão valida a explicação do vencedor e faz revisionismos históricos que justificam os erros do mártir vencido.

Palavras-chave: Colombia, Nova Granada, historia, guerra, independência, monumento histórico. 


\section{Introducción}

Las representaciones históricas, resultado del estudio e interpretación de lo acontecido desde las artes de la política, la guerra, los negocios o la expresión cultural ${ }^{1}$, así como desde las artes plásticas, literarias y demás expresiones estéticas, han propiciado una naciente e innovadora historia hibrida ${ }^{2}$ como alternativa a los relatos positivistas, los determinismos materialistas o las historias totales que desprecian y condenan el uso de las expresiones culturales subjetivas ${ }^{3}$.

En su crítica a la historia e historiografía alemanas, F. Nietzche destacaba ya la coexistencia, ironías y contradicciones que se generaban cuando cada hecho del pasado se sometía a las perspectivas del momento interno del testigo histórico en contraste al monumento y la monumentalidad externa de lo acontecido. Contrastes que demandaban una disciplina interpretativa, la cual reconociera los beneficios y perjuicios de confiar la explicación de lo acontecido a tan solo una posibilidad argumental: el omnipotente archivo histórico y los vestigios de verdad allí acumulados. De allí el recurrente cuestionamiento a que una subjetividad histórica seleccione, construya y divulgue su versión objetiva de lo que se considera verdaderamente ha sucedido, apelando a su privilegiada condición de autoridad histórica ${ }^{4}$, sin considerar otras fuentes, visiones, interpretaciones e intérpretes acerca de ese mismo acontecimiento (memoria colectiva).

Ejemplo de representaciones históricas por revisar y reconstruir son los relatos asociados con la caída de la primera república, la reconquista española y el restablecimiento del régimen virreinal neogranadinos, los cuales son estudiados en este artículo a partir de las vicisitudes, derrotas y monumentos al accionar militar del General Custodio García Rovira durante la Batalla de Cachirí.

Entre el 21 y 22 de febrero de 1816, en el paso más extremo del páramo de Cachirí en la provincia de Pamplona, se enfrentaron de forma decisiva las tropas de la división realista que había ascendido desde los llanos del Casanare contra la versión mejorada del primer ejército nacional neogranadino, compuesto por batallones de diferentes Provincias y Estados. Ejército cuyo propósito era enfrentar la amenaza a la soberanía nacional y a la continuidad del régimen republicano representado por el Congreso de las Provincias Unidas, siendo congregados en Piedecuesta reclutas enviados desde Bogotá, Socorro, Pamplona y los reductos que habían huido desde Cartagena 5 .

\footnotetext{
${ }^{1}$ Perkowska, Magdalena. Historias híbridas. La nueva novela histórica latinoamericana (1985-2000) ante las teorías postmodernas de la historia (Madrid-España: Iberoamericana, 2008).

${ }^{2}$ Pérez, Luis. Narrativa, memoria y heroísmo empresarial. Historia híbrida de la guerra, el conflicto y el empresariado de Santander (Colombia) desde mediados del siglo XIX (Bucaramanga: Ediciones UIS, 2015), cap. 1.

${ }^{3}$ Silva, Renán. A la Sombra de Clio: Diez ensayos sobre historia e historiografia (Bogotá: La carreta, 2007).

${ }^{4}$ Nietzche, Federico. Sobre los beneficios y perjuicios de la historia para la vida (1874) (Madrid: Gredos, 2009 )

${ }^{5}$ Duque Muñoz, Lucía y Montoya Garay, Jhon Williams. Impactos territoriales en la transición de la
} 
Todos bajo el mando del General Custodio García Rovira, reconocido líder político, gobernador, comandante militar y promotor jurídico del proyecto republicano federalista, respaldado por el experimentado coronel Francisco de Paula Santander como su segundo comandante.

El descomunal triunfo a favor de los realistas dejó sin defensa ni resistencia la penetración del ejército expedicionario hasta la capital republicana, permitió el restablecimiento del régimen virreinal en representación del monarca Fernando VII, así como degeneró en una guerra irregular por medio de guerrillas itinerantes y ejércitos periféricos por parte de los militares y caudillos republicanos que habían escapado al accionar de los tribunales de purificación realista ${ }^{6}$. Sin embargo, para los historiadores del centenario como del bicentenario de la Independencia de Colombia, el nombre, la figura y las cuestionadas capacidades militares del erudito bumangués han sido adaptadas a la condición de "sujeto patrimonial"7 de la historia regional de Colombia, a través de sus crónicas y monumentos ${ }^{8}$.

Reconstruir un acontecimiento bicentenario como lo es la Batalla de Cachirí y las decisiones de los comandantes que guiaron a los ejércitos internacionales en disputa (neogranadinos aliados con venezolanos, franceses, ingleses, estadounidenses, etc., contra españoles y venezolanos realistas), conlleva a reconocer las preocupaciones, los temas y los problemas de cada una de las generaciones que han rescatado y redimensionado lo acontecido. Así mismo, permite interpretar los propósitos de las construcciones culturales posteriores, magnificadas con monumentos, expresiones monumentales y una monumentalidad ideologizante.

Problemas historiográficos que exigen dar respuesta a cuestionamientos como el siguiente: ¿por qué un héroe deshonrado, despreciado y olvidado por la historiografía que da cuenta del éxito de la revolución independentista y la formación de la República de Colombia fue perpetuado en los monumentos locales, los imaginarios regionales y las representaciones nacionales sobre los mártires de la Campaña Libertadora?

Para tal fin, es revisado y redimensionado el papel que ha tenido la reconstrucción interpretativa de las tres generaciones de historias e historiadores que han revisado y explicado los sucesos de la independencia y la Campaña Libertadora. Estas versiones son contrastadas con los relatos y discursos ideológicos de los libros oficiales de lectura e historia patria, los monumentos patrios en las plazas, museos y edificios públicos, así como el fomento de versiones monumentales de lo acontecido por las diferentes

Colonia a la República de la Nueva Granada (Bogotá: Universidad Nacional de Colombia, 2013).

${ }^{6}$ Pérez, Eduardo. Guerra irregular en la independencia de la Nueva Granada y Venezuela (Tunja: Universidad Pedagógica y Tecnológica, 1982).

${ }^{7}$ Balbo, Marcelo; Jordán, Ricardo y Simioni, Daniela (comps.). La ciudad inclusiva (Santiago de Chile: Cepal, 2003).

${ }^{8}$ Pérez, Luis. "Emancipación política, resistencia ideológica y contra-hegemonía cultural en los discursos sobre la independencia. La condición 'revolucionaria' del ser colombiano primigenio", en Historiar la muerte. II Representaciones sociopoliticas sobre el 'buen morir por la patria' entre los revolucionarios de Colombia, editado por Luis Rubén Pérez Pinzón, 2014, pp. 271-326 
tendencias y corrientes historiográficas que estudian el proceso de independencia bélica de Colombia.

\section{La generación del centenario}

La Batalla de Cachirí y la derrota del general bumangués José Custodio Cayetano García Rovira (1780-1816) entre el atardecer del miércoles 21 y el amanecer del jueves 22 de febrero del año bisiesto de 1816, se constituyeron en acontecimientos decisivos para comprender los orígenes de la actual Colombia como república unitaria, nacional, independiente y soberana ante las pretensiones de reconstitución política y recomposición territorial de los reinos que conformaban el imperio de España ${ }^{9}$ por parte de la generación conservadora y nacionalista asociada con la Regeneración. Esos acontecimientos también se asumieron como el origen de la guerra de liberación concebida como un conflicto internacional, planificado y dirigido desde las llanuras de la Orinoquía desde 1817, en el cual intervinieron activamente oficiales y soldados de diferentes Naciones y Estados.

El ejército neogranadino derrotado en la Batalla de Cachirí fue la primera manifestación de un ejército nacional dispuesto a enfrentar a un enemigo externo común con soldados provenientes de las provincias que aún permanecían emancipadas o independientes, así como con voluntarios y mercenarios llegados desde otras naciones europeas enemigas de España ${ }^{10}$. Así mismo, la coyuntura pacificadora y reconquistadora condicionó a los residentes neogranadinos de origen francés, escocés, irlandés, inglés, estadounidense, jamaiquino, etc., en las provincias libres, así como aquellos huidos desde las provincias de Cartagena y Maracaibo, a unir sus esfuerzos por la causa americana y reafirmar la condición hemisférica que adquirió el conflicto bélico neogranadino ${ }^{11}$.

La derrota de C. García Rovira como uno de los últimos presidentes y generales de la primera república (1810-1816) fue tan contundente y vergonzante que simbolizó la derrota política y la huida de los ideólogos de las Provincias Unidas de la Nueva Granada, la incapacidad de los militares neogranadinos de contener al experimentado ejército expedicionario y de pacificación para la tierra firme, así como uno de los hechos de la historia militar colombiana de mayor olvido, desconocimiento e impopularidad por las equivocas decisiones de estrategia y táctica en el teatro de operaciones, al estar condicionados los comandantes por las presiones y limitaciones del régimen federal provincial. El régimen que contradictoriamente estaba centralizado en Santafé de Bogotá al preservarse la impronta del despotismo ilustrado borbónico ${ }^{12}$.

\footnotetext{
${ }^{9}$ Ibid.

${ }^{10}$ Brown, Matthew. Adventuring through Spanish Colonies: Simón Bolivar, Foreing Mercenaries and the Birth of New Nations (Liverpool: University of Liverpoool Press, 2006).

${ }^{11}$ Earle, Rebecca. Spain and the Independence of Colombia, 1810-1825 (Chicago: University of Exeter Press, 1999).

${ }^{12}$ Villar, Pierre. Historia de España (Barcelona: Editorial Grijalbo, 1978). Pérez, Luis. Los socorros de Nuestra Señora del Socorro, El Socorro y los socorranos a la independencia del centro-oriente de Colombia (Bogotá: Presidencia de la República, 2010), http://www.bicentenarioindependencia.gov.co/Es/ Documents/LosSocorrodeNuestraSenoradelSocorro.pdf.
} 
La funesta Batalla de Cachirí se constituyó a su vez en el peor descalabro de toda la guerra libertadora neogranadina (1816-1819). El número de bajas en soldados (más de mil quinientos entre Balagá y Cachirí), caballos (más de cuatrocientos), prisioneros de guerra (doscientos heridos, quinientos en presidios) parque (dos piezas de artillería, cuatro banderas de batallón, 750 fusiles, 300 lanzas, 45.000 cartuchos) y logística de campaña (provisiones, ganados, material de intendencia, etc.), fue de proporciones superiores a lo acontecido durante la decisivas batallas neogranadinas en Vargas y Boyacá, entre julio y agosto de 1819 .

Esa tradición oral e institucional de la historia colombiana fue permeada y reafirmada durante las siguientes generaciones por la versión oficial dictada y memorizada desde 1910 en las escuelas públicas, a partir del compendio de historia de Colombia propuesto por Jesús Henao y Gerardo Arrubla como parte de los monumentos conmemorativos del centenario. Su versión de lo acontecido explicaba los reveses de la naciente nación como del reputado doctor en leyes al fracaso mismo de la primera república, asumida y estigmatizada de forma despectiva como la época de la "Patria Boba"13. Desde esa perspectiva, con la batalla de Cachirí culminó la primera etapa republicana de conflictos elitistas, pugnas fragmentarias entre provincias, indefiniciones sobre el modelo republicano a seguir y los desacuerdos sobre la lealtad o insurrección por las élites provinciales.

El período republicano de 1810 a 1816 fue de inexperiencia y múltiples errores promovidos por jóvenes ingenuos y universitarios idealistas, sin un heroico líder militar (el general-libertador) y un genio político unificador (el ciudadano-presidente) como el surgido con la independencia libertadora (Simón Bolívar). Un período pueril del Estado Nación colombiano ante el cual se pedía a las generaciones republicanas del siglo XX recordar a los padres de la patria como patriotas que:

Empeñábanse, es verdad, pero de buena fe, en lucha armada los pequeños bandos y las importantes cuestiones del gobierno se trataban con alteza de miras; pero las discusiones sobre rivalidades parroquiales, títulos y detalles minúsculos en las horas en que era preciso cerrar filas para conservar lo adquirido, con energía y valor, recuerdan las disputas bizantinas de tiempos lejanos ${ }^{14}$.

\footnotetext{
${ }^{13}$ El análisis regional de la Primera República como una "patria boba" de conflictos y pugnas entre elites provinciales, acorde a la crítica de Antonio Nariño, ha hecho parte de la reflexión historiográfica de: Martínez, Armando. El Legado de la Patria Boba (Bucaramanga: Sistemas y Computadores, 1998); Pérez Pinzón, Luis Rubén. Historia bicentenaria de un día de revolución (Bucaramanga: Ediciones UIS, 2007). Siendo reafirmado ese enfoque sobre los efectos de las luchas provinciales en la consolidación de la república anhelada desde las representaciones historiográficas nacionales por: Reyes, Ana Catalina. "La difícil tarea de construir la Unidad Nacional: La fuerza de las soberanías locales en la Primera República de la Nueva Granada 1810-1816", Todos somos Historia-Unión Rebeldía e Integración (Medellín: Imprenta Universidad De Antioquia, 2010); Gutiérrez Ardila, Daniel. Un Nuevo Reino. Geografia política, pactismo y diplomacia durante el interregno en Nueva Granada (1808-1816) (Bogotá: Universidad Externado de Colombia, 2010). Investigadores extranjeros han reafirmado las consecuencias de esas rupturas geográficas y autonomías sociopolíticas en el fracaso estatal de la primera república como ha sido el caso de: Earle, Rebeca. España y la Independencia de Colombia (Bogotá: Uniandes Banco de la República, 2014); Safford, Frank y Palacios, Marco. Colombia: País fragmentado, Sociedad dividida (Bogotá: Editorial Norma, 2002).

${ }^{14}$ Henao, Jesús y Arrubla, Gerardo. Historia de Colombia para la enseñanza secundaria, tomo II (Bogotá: Librería Colombiana. Camacho Roldán \& Tamayo, 1920), p. 305.
} 
Desde la visión republicana, nacionalista y regeneradora del centenario, promovida en sus textos didácticos por J. Henao y G. Arrubla, C. García Rovira ${ }^{15}$ no estuvo al mismo nivel heroico y legendario de otros generales y presidentes republicanos ${ }^{16}$.Esto dado que como Presidente de las Provincias Unidas y como General del Ejército de la Unión sus decisiones y acciones estuvieron directamente asociadas con la "ruina de la República" $"$. Sin embargo, desde las primeras ediciones de su Historia fue agregada una fotografía del monumento erigido al prócer en su ciudad natal de Bucaramanga en enero de 1907, fundido en Francia gracias a las gestiones de la colonia alemana e inaugurado con el fin de enaltecer los actos de conmemoración del centenario independentista de la emancipación, siendo recordado su nombre y gestas como prócer y caudillo de la primera república, así como la exaltación desde 1916 como mártir y héroe que promovió la independencia emancipadora.

La estatua en bronce de Bucaramanga y su monumento marmóreo de tres niveles, acompañado de escudos de Colombia y placas alegóricas a lo acontecido en 1816, conllevaron a cambiar esa plaza en el Parque García Rovira, el barrio del centro fue renombrado como el barrio García Rovira durante el siglo XX, así como durante el siglo XXI el conjunto de barrios de la comuna cinco fueron nombrados y advocados en memoria del General Presidente, quien había nacido en una de las casas y calles de su jurisdicción.

El uso simbólico y patrimonial del nombre y apellidos de Custodio García Rovira también fue empleado por las autoridades municipales, departamentales y nacionales para crear y nombrar la Provincia de García Rovira (1854), el Colegio Nacional Custodio García Rovira de Málaga (1950), el Monumento Nacional Casa natal de Custodio García Rovira en Bucaramanga (1966), la Institución Educativa Inem Custodio García Rovira de Bucaramanga (1970), la Casa de la Cultura Custodio García Rovira de Bucaramanga (1975), el hospital regional García Rovira de Málaga (1995). Así mismo, han existido los Batallones de Infantería General Custodio García Rovira con sede en Pamplona (1931) y Bucaramanga (1971), la Academia Militar Custodio García Rovira en Manizales y el Instituto Integrado Custodio García Rovira en Puerto Inírida (Guainía). Los antioqueños crearon en 1903 una estampilla conmemorativa ${ }^{18}$, así como cambiaron de nombre a la carrera 38 de Medellín, al pasar de ser la carrera Bélgica a la Carrera García Rovira ${ }^{19}$.

No obstante, desde la memoria colectiva de los testigos de lo acontecido en 1816, la derrota y muerte del prócer neogranadino, a la par de la caída de la primera república

\footnotetext{
${ }^{15}$ Ocampo López, Javier. "Custodio García Rovira”, en Biografías Biblioteca virtual del Banco de la República, 2010, http://www.banrepcultural.org/blaavirtual/biografias/garccusto.htm.

${ }^{16}$ Baraya, José María. Biografias militares: o, historia militar del país en medio siglo (Bogotá: Imprenta de Gaitán, 1874).

${ }^{17}$ Henao, Jesús y Arrubla, Gerardo, Op Cit., p. 338.

${ }^{18}$ Colombia, Departamento de Antioquia. Estampilla conmemorativa del General Custodio García Rovira (Medellín: Litografía Arango, 1903).

${ }^{19}$ Rodríguez, Pedro. Significado histórico del nombre de algunas calles y carreras de la ciudad de Medellín (Medellín: Instituto Tecnológico Metropolitano, 2004).
} 
y el sistema de libertades por el que habían peleado, estaba justificada desde la perspectiva de los veteranos de la primera república. José María Caballero escribió en su diario, en lo concerniente a los hechos de agosto de 1816: "A 8 decapitaron a García Rovira, general que fue de las tropas de la Unión, y el que perdió por su impericia el ataque de Cachirí, pues si él se porta como buen militar, no era Morillo el que había entrado a esta ciudad"20.

\section{La primera generación republicana}

Las versiones y juicios de J. Henao y G. Arrubla sobre lo acontecido durante la "Patria Boba", desde su condición como ganadores de la mejor representación histórica de la generación centenarista, no estuvieron sustentadas en fuentes históricas de archivos oficiales ni en versiones directas de testigos de lo acontecido. Por el contrario, sus relatos fueron resúmenes hechos de forma directa y literal de los libros, testimonios e interpretaciones subjetivas, partidarias o sesgadas que fueron publicadas por los funcionarios y militares que conformaron la generación republicana desde 1810 .

Los dos miembros de la Academia de Historia de Colombia optaron por resumir y dar como incuestionable lo relatado en la "Historia de la revolución de la República de Colombia” (París, 1824-1827), de José Manuel Restrepo Vélez (1781-1863). Fuente primaria de los acontecimientos al desempeñarse como diputado y gobernador provincial, constitucionalista, magistrado y Secretario de Estado del General Presidente Simón Bolívar.

Según J. Restrepo, los errores estratégicos y el exceso de confianza en las tácticas de los generales republicanos justificaron "las reliquias miserables del ejército granadino", cuyos restos fueron reagrupados tardíamente en agosto de 1816 en Guasdualito (Casanare $)^{21}$, a falta de un plan de retirada, resistencia y depósito de armas en los Llanos de Oriente ${ }^{22}$. También reafirmó las causas políticas que influyeron en la pérdida de la independencia y libertad de la primera república neogranadina al reflejarse en los campos de batalla de la ciudad 'fortificada' de Cartagena, el 'páramo' de Cachirí y la 'cuchilla' de El Tambo lo acontecido en los campos del poder, al interior del Congreso de las Provincias Unidas y del Gobierno General concentrado en Santafé.

A falta de unidad en el mando entre las milicias provinciales y los oficiales del ejército reglado de las Provincias Unidas al mando de generales extranjeros, Calzada y sus hombres lograron descansar tranquilamente, reorganizar sus batallones y continuar su avanzada hacia Pamplona y Ocaña. Lo cual se reflejó en la derrota del Gobernador F. Serrano y el General R. Urdaneta en la batalla de Balagá (Chitagá, sábado 25 de noviembre de 1815) ${ }^{23}$, lo cual facilitó el ascenso y protagonismo del General C.

\footnotetext{
${ }^{20}$ Caballero, José María. Diario de la independencia (1816) (Bogotá: Biblioteca virtual Banco de la República, 2005), http://www.banrepcultural.org/blaavirtual/historia/diarioindep/diario9c.htm\#11.

${ }^{21}$ Restrepo, José Manuel. Historia de la revolución de la República de Colombia (Medellín: Bedout, 1974), p. 130.

${ }^{22}$ Ibid., p. 132.

${ }^{23}$ Ibid., p. 94.
} 
García Rovira al ser el único militar de confianza y experticia que podía afrontar la defensa de las provincias del Norte. Su ingreso en la guerra de resistencia como sus reiterativos combates contra S. Calzada fueron presentados por J. Restrepo de la siguiente manera: "El General García Rovira, que obtenía el mando de lo que se llamaba Primer Ejército de reserva, que sobre el papel debía constar de cuatro mil hombres, salió del Socorro avanzándose hasta la villa de Málaga, con el designio de completar la destrucción de los fugitivos de Chire"24.

C. García Rovira y F. Santander debían aprovechar su superioridad bélica de "[...] dos mil quinientos soldados, los mil seiscientos fusileros con poco más de cien jinetes, y el resto armados de lanzas" ${ }^{25}$ para: contener el avance de la división realista a Santafé, destruirla o alejarla lo mayor posible de la capital neogranadina; apoderarse y asegurar la ruta por donde se esperaba la avanzada del grueso del ejército expedicionario desde Mompox y Ocaña hacia el Nuevo Reino; y en especial, para extinguir los excesos morales que se cometían por causa de la inacción de los republicanos en la defensa de los pueblos ${ }^{26}$.

Sin embargo, la derrota sufrida en una proporción de quince republicanos muertos por cada uno de los realistas dados de baja entre Balagá y Cachirí, redujo al esperanzador Ejército del Norte a doscientos hombres con sus comandantes ecuestres al reunirse en El Socorro. Mientras tanto, en el campo de batalla "no se salvaron treinta hombres reunidos", al quedar atrapados la mayor parte de los combatientes entre las trincheras construidas para su defensa como entre el fuego cruzado de los realistas.

Al apelar a las partes de guerra y a las memorias de los oficiales que estuvieron presentes en Cachirí, una década después de la derrota patriota, J. Restrepo explicó lo acontecido a las generaciones de republicanos del siglo XIX, de la siguiente manera:

Según los vencedores, el yerro capital de Rovira en esta acción fue haber querido hacer con tropas bisoñas la defensa por escalones, cuando sólo es dado hacerla con las que son aguerridas. Aseguraron también algunos jefes de aquel ejército que si el combate se hubiera sostenido de firme en la posición, el enemigo hubiera sido rechazado y acaso destruido ${ }^{27}$.

\section{La generación del bicentenario}

La explicación de las causas y consecuencias de lo acontecido en Cachirí en 1816, apelando a las fuentes del vencedor como fuente presencial, neutral y confiable de lo acontecido, se ha constituido en una alternativa de análisis y contraste recurrente para cuestionar los propósitos de un discurso académico unificado como historia patria.

\footnotetext{
${ }^{24}$ Ibid., p. 74

${ }^{25}$ Ibid., p. 95.

${ }^{26}$ Ibid.

${ }^{27}$ Ibid.
} 
La revisión de los archivos, las memorias y los relatos del vencedor para validar la versión heroica del vencido, ha sido empleada de forma recurrente por la generación de investigadores encargada de conmemorar el bicentenario de la Independencia de la actual República, tanto en su celebración emancipadora (1810-2010) como en la libertadora (1819-2019). Un ejemplo es el espíritu independentista que ha animado a la Academia de Historia de Santander, órgano asesor y promotor de la memoria oficial del Departamento de Santander.

En la primera sesión ordinaria de 2016, conmemorativa de la Batalla de Cachirí, el Presidente de esa corporación cívica, académica y cultural lideró la reunión de los miembros que se hicieron presentes al proponer una reflexión documentada sobre lo acontecido en febrero de $1816^{28}$, optando por la perspectiva de la exaltación del fracaso como principio de unidad y orgullo nacional adoptado por otras naciones latinoamericanas. Para ello se reivindicó la confianza, seguridad y autoridad conferida a las fuentes históricas conservadas en los archivos históricos de España y Colombia acerca del mártir, prócer y derrotado más conocido por los bumangueses. Culto consecuente a los actos protocolarios promovidos por la generación del centenario y las construcciones monumentales creadas o nombradas para perpetuar su nombre desde 1907.

Una primera revelación documental ${ }^{29}$ fue la autodeclarada inexperiencia y habilidad de C. García Rovira como General, al expresar el 13 de enero de 1816 desde su condición como doctor en leyes y exgobernante político de la federación, no poseer: “[...] todos los conocimientos de una profesión que no ha sido la mía, como por otros obstáculos que son propios del tiempo"30. Su amor por la música y la lectura eran incompatibles con las artes de la guerra y las política, aunque debía acatar las órdenes del Presidente Camilo Torres, quien le ordenó encargarse de la Autoridad militar y política (gobernador) de Tunja y El Socorro.

Otra revelación fue la abierta y sistemática oposición del segundo al mando del Nuevo Ejército del Norte, el General Francisco de Paula Santander, a permanecer, acuartelar y defender el paso de Cachirí. Santander había cumplido sus obligaciones "en la vanguardia en los días del combate" pero en sus "Apuntamientos" declaró que durante las conferencias de generales "[...] me opuse al plan de defender la montaña de Cachirí colocando las tropas por escalones para hacer una retirada a Bucaramanga" ${ }^{\prime 1}$.

\footnotetext{
${ }^{28}$ Martínez, Armando. La reconquista del centro del Nuevo Reino de Granada (Bucaramanga: Academia de Historia de Santander, 2016), 10 p.

${ }^{29}$ Martínez, Armando. Disertación de la sesión ordinaria de la Academia de Historia de Santander: La batalla de Cachirí (Bucaramanga: Academia de Historia de Santander, 2016).

${ }^{30}$ García Rovira, Custodio. "Comunicación dirigida a Andrés Rodríguez, secretario de Guerra del gobierno general de las Provincias Unidas de la Nueva Granada" [Cuartel general del Pie de la Cuesta, 13 de enero de 1816], en Cacua Prada, Antonio, Custodio García Rovira. El estudiante mártir (Bogotá: Academia Colombiana de Historia, Plaza \&Janés, 1983), p. 133.

${ }^{31}$ Santander, Francisco de Paula. Apuntamientos para las memorias sobre Colombia i la Nueva Granada (Bogotá, Imprenta de Lleras y Compañía, 1837).
} 
El General C. García Rovira estaba "dotado de un valor personal admirable y empapado con muchas teorías militares"32, especialmente las historias militares francesas. Aunque al aplicar esos conocimientos en el campo de batalla, durante el fragor del combate, no consideró lo inviable que era llevar a cabo con tropas bisoñas aquello que había resultado exitoso entre los grandes capitanes del pasado, quienes habían estado al mando de tropas veteranas y "bien disciplinadas" ${ }^{33}$. Por el contrario, los reclutas forzados con los que contaba C. García Rovira reflejaban el desánimo moral de las gentes comunes en favor de la independencia después de la caída de Cartagena y la derrota del ejército independentista en Chitagá ( 25 de noviembre de 1815). De allí que ante la fugaz confianza ganada por los inexpertos guerreros durante su primer combate en Cachirí se desvaneciera al sentirse aprisionados y condenados a una muerte brutal de permanecer ocultos en las fortalezas escalonadas (o trincheras) dispuestas por C. García Rovira para defenderse y asegurar la gradual retirada de los batallones más débiles hacia Bucaramanga ${ }^{34}$.

Así mismo, eran evidentes las desavenencias entre los comandantes porque, desde la perspectiva de Santander, veinte años después de la derrota, una batalla desde una fortaleza requería contar con veteranos aguerridos como los que habían estado bajo su mando en Cúcuta y Ocaña, siendo ello una situación que no caracterizaba los batallones de reclutas, disciplinados de forma apresurada e inconclusa en el cuartel de Piedecuesta. A partir de esto, la mayoría de los combatientes de Cachirí eran "tropas tan bisoñas, que más de la mitad de los soldados apenas se habían fogueado antes de ver por primera vez al enemigo" 35 .

Ese permanente cuestionamiento y desautorización a las decisiones del primer comandante por parte del coronel F. Santander, le fueron reprochadas dos décadas después por sus adversarios bolivaristas al expresarle que había sido tan cobarde como García Rovira, al recordarle que: "Llegamos a la célebre acción de Cachirí. V. como segundo recibió órdenes del jefe para dar las disposiciones necesarias para el combate, ¿y cuáles dio? -Ninguna. Se gloría de haber estado en la vanguardia, y seguramente V. sería de los primeros de atrás [...] Todavía viven testigos de estos hechos"36.

Cuestionamientos a los que respondió públicamente el General Presidente en sus “Apuntamientos", expresando que la derrota y retirada en Cachirí eran consecuencia de la inexperiencia de los soldados que se enfrentaron a veteranos de batallas regulares en Europa e irregulares en el Casanare como de la improvisación en ingeniería militar

\footnotetext{
32 Ibid., p. 13.

${ }^{33}$ Sevilla, Rafael. Memorias de un oficial del Ejército Español. Campañas contra Bolívar y los separatistas de América (Madrid: América, 1916); Escosura, Jerónimo de la. Biografia del teniente general Don Pablo Morillo, Conde Cartagena, Marqués de la Puerta, caballero gran cruz de la real y distinguida orden de Carlos $3^{\circ}$, de la militar de San Fernando, de la americana de Isabel la Católica y caballero de la de San Hermenegildo, gentilhombre de cámara de S.M. etc., etc. (Madrid: Real Academia de la Historia, 1840).

${ }^{34}$ Martínez, Armando. La batalla de Cachirí (El Socorro: Academia de Historia de Santander, 2016).

${ }^{35}$ Santander, Francisco, Op. Cit., p. 13.

${ }^{36}$ Colombia, Documentos. 12 Cartas dirigidas al Ex-Jeneral Francisco de Paula Santander por los Cincuenta (Bogotá: Imprenta por José Avarza, 1837), p. 20.
} 
por la que optó C. García Rovira al pertrecharse. También culpó al Gobierno General, presidido por Camilo Torres, quien "[...] no tomó de antemano todas las medidas activas para crear la fuerza armada necesaria para defender el país" ${ }^{\prime 37}$, desde que se conoció la llegada del ejército expedicionario a Venezuela.

Así, el carácter guerrero y temerario del que carecían los reclutas bisoños de los batallones neogranadinos enviados desde Bogotá, Socorro, Pamplona, Piedecuesta y sus alrededores, era opuesto al compartimiento bélico de las experimentadas tropas de la quinta división realista, dispuestas a enfrentar las adversidades que les oponían a los europeos: tanto la naturaleza y el clima como las gentes americanas. Razón por la cual, eran “[...] tropas acostumbradas a derramar su sangre en defensa de su Rey, como tantas veces lo han acreditado; estando firmemente persuadido que no desmentirán su carácter bizarro en cuantas ocasiones se ofrezcan, el cual les llevará a despreciar la muerte y correr a la victoria, hollando los peligros", para "cubrirse de gloria" con sus "gloriosas acciones" 38 .

Habían sido tropas entrenadas y disciplinadas en la valentía, el terror y la disciplina ante pueblos adversos como parte de un permanente accionar militar en las cálidas llanuras como en los gélidos páramos, cuyas penurias fueron resumidas por S. Calzada de la siguiente manera:

Quien conozca lo desierto de estos países, lo áspero, inculto y horroroso del terreno, desde que se dejan los Llanos de Casanare, lo peligroso de los diversos páramos de la cordillera colocados a más de dos mil toesas sobre el nivel del mar, envueltos en ventiscas y hielos, hombres de países tan cálidos como lo son los Llanos de Barinas, mirará dicha campaña como una cosa fabulosa ${ }^{39}$.

Con la "completa derrota del exército enemigo" al ocuparse durante los días siguientes Pamplona y Cúcuta y no encontrarse con la resistencia de los infantes bisoños del extinto ejército del Norte que las defendían, aunado a la apertura y control de Cachirí como la única posición independentista que impedía la avanzada de las tropas realistas desde Mompox hacia Santafé, el General P. Morillo, una semana después del parte de victoria de S. Calzada, informó la finalización de su misión pacificadora en el norte de la Nueva Granada. Para ello, expresó al Secretario Universal de la Guerra en España: “[...] para no perder esta ocasión, la más favorable para recuperar el Reyno e impedir la reunión de cualquiera otro Exército, marcho aceleradamente sobre sus miserables reliquias, prometiéndome no encontrar ya ni un solo soldado en todo el Reyno, y por consiguiente está a nuestro arbitrio" ${ }^{\prime 40}$.

\footnotetext{
${ }^{37}$ Santander, Francisco, Op. Cit., p. 13.

${ }^{38}$ Morillo, Pablo. "Comunicación al Secretario de Estado y Despacho Universal de la Guerra, Cuartel General de Mompox, 29 de febrero de 1816”, en Real Academia de la Historia (RAH), España, Colección de don Pablo Morillo, conde de Cartagena, Madrid, Libro copiador de oficios despachados, núm. 19, folios 15-16, fotos 35-38.

${ }^{39}$ Morillo, Pablo, Op. Cit., pp. 15-16

${ }^{40}$ Morillo, Pablo. "Comunicación al Secretario de Estado y Despacho Universal de la Guerra, Cuartel General de Mompox, 27 de febrero de 1816”, en Real Academia de la Historia (RAH), España, Colección de don Pablo Morillo, conde de Cartagena, Madrid, libro copiador de la correspondencia enviada por el general Pablo Morillo. folios 125v-126v, fotos 248-250.
} 


\section{Mitos, leyendas y creencias populares}

La versión legítima de lo acontecido que fue promovida a través de los libros y publicaciones de la historia patria, los cuales fueron empleados como textos de instrucción popular y manuales de instrucción pública, así como los esfuerzos de la generación del bicentenario por recopilar y publicar documentos de cada fecha a conmemorar para formar a las generaciones contemporáneas en las versiones y visiones de lo acontecido de manera fidedigna, requieren ser contrastadas con los contradiscursos históricos y las variaciones anacrónicas que caracterizan las versiones populares y la memoria local de las comunidades que habitan los lugares históricos mencionados en cada conmemoración y celebración de la Independencia colombiana.

Ejemplo de ello son las versiones, relatos y recuerdos que sobre lo acontecido en febrero de 1816 son divulgados por los guías turísticos, los maestros rurales y los líderes comunales que habitan el corregimiento de Cachirí, jurisdicción del Municipio de Suratá (Santander). Ciudadanos con una versión de verdad sobre lo que pasó que es contraria a las versiones oficiales de la generación republicana, a las académicas de la generación de historiadores del centenario y a las interdisciplinarias de los investigadores sobre el bicentenario.

Para el ciudadano José Giovanni Lizcano Rincón, desde su condición como nativo ilustrado, líder comunal, historiador local y presidente de la Junta de Acción Comunal de la vereda Cachirí (Suratá), quien desconoce los documentos, libros y memorias de los protagonistas de la revolución emancipadora, la reconquista y la independencia libertadora, lo que sucedió en la Batalla de Cachirí está asociado a una piedra gigantesca, de forma piramidal, desde la cual se desencadenaron los demás hechos que caracterizaron la campaña libertadora de las guerrillas y el ejército patriota. Piedra que se constituye en atractivo e ícono local para la visita turística y la reflexión histórica al estar ubicada en un terreno plano, de fácil y corto acceso desde el casco urbano. Para no ser confundida, en su cima es izada permanentemente un pabellón nacional.

Esa tradición de lo acontecido desde la memoria colectiva de las comunidades campesinas que ocupan el lugar, dicta que exactamente en ese lugar ocurrió el teatro de operaciones y la batalla definitiva que enaltece a sus moradores, siendo recordado a propios y visitantes que el mayor honor y orgullo que pueden tener los cachirenses es que el General pidió allí a sus hombres armarse del coraje, valor y osadía propios de los americanos al gritarles: “¡Firmes Cachirí!”.

Frase emblemática que ninguna de las fuentes documentales ni los testigos de la Batalla, tanto españoles como neogranadinos, aseguran fue pronunciada en el momento de mayor estupor por el comandante neogranadino. Por el contrario, en otras versiones como la de los vencedores españoles de esa batalla esta frase fue empleada por iniciativa y petición del General P. Morillo al rey Fernando VII, quien decidió renombrar a uno de sus batallones como Cachirí para rememorar su heroísmo, los premios y ascensos obtenidos, así como por la consecuencia militar de ese triunfo contra los republicanos neogranadinos. Batallón cuya existencia 
fue reconocida un año después, durante la campaña libertadora de Venezuela, al enfrentarse los ejércitos de Miguel de la Torre y Manuel Piar en la batalla de San Félix (Angostura, 11 de abril de 1817). En este contexto, los soldados animados por el gobernador y los comandantes realistas, se preparan para entrar en batalla con un grito unánime: “¡Firmes Cachirí!”41.

También, desde la memoria monumental y anticuaria de los pedagogos e historiadores de la segunda mitad del siglo XIX se creó y estableció una versión legendaria sobre lo acontecido en Cachirí, según la cual, el gran derrotado había promovido un acto desesperado de valor y arrojo propio del estereotipo de los valientes socorranos y pamploneses $^{42}$. Acto que a la par de los monumentos existentes en las demás capitales territoriales de Colombia a los próceres, mártires, caudillos o libertadores de la independencia, ameritaba perpetuar su memoria, visitando los lugares de cada gesta ${ }^{43}$, así como reafirmando la identidad nacional con una gesta narrada en los manuales escolares sobre la historia colombiana, publicados desde mediados del siglo XIX. Ejemplo de ello es el manual del historiador y pedagogo bogotano José María Quijano Otero, quien aseguraba que el general-estudiante se inmortalizó con su: "Firmes Cachirí" ${ }^{4}$.

\section{Conclusión}

La revisión de las representaciones sobre los acontecimientos asociados con la caída de la primera república, la reconquista española y el restablecimiento del régimen virreinal neogranadinos, demuestran que para la historiografía fundacional de la República como para los historiadores del centenario y el bicentenario de la independencia de Colombia, el nombre, la figura y las cuestionadas capacidades militares del General Custodio García Rovira han trascendido y contrariado las historias institucionales y los textos didácticos después de doscientos años de su existencia.

Durante cada centenario republicano es redimensionado su culto y hazañas desde la condición de ilustrado, prócer, caudillo, mártir, general-presidente, patriota, etc., de la Independencia neogranadina, anteponiéndose a sus prácticas intelectuales, excesos políticos y fracasos militares, una monumentalidad ideológica, didáctica, escultórica y territorial que ha asociado su nombre con las virtudes, ideales y convicciones emancipadoras del ciudadano republicano primigenio. Reflejo de lo anterior es representado por la asociación del ethos santandereano con la frase: "Firmes Cachirí", supuestamente manifestada por el prócer sobre una piedra garante de su cuestionada gesta acorde a la memoria popular.

\footnotetext{
${ }^{41}$ Baralt, Rafael María y Díaz, Ramón. Resumen de la historia de Venezuela desde el año de 1797 hasta el de 1850 (París: Imprenta de H. Fournier y compañía, 1841).

${ }^{42}$ Colombia, Gobernación de Santander. Centenario de Custodio García Rovira en Bucaramanga, 1816 -8 de agosto-1916 (Bucaramanga: Taller Gráfico, 1916).

${ }^{43}$ Ancízar, Manuel. Peregrinación de Alpha (M. Ancizar) por las provincias del norte de la Nueva Granada, en 1850 i 1851, cap. XXXII (Bogotá: Imprenta de Echeverría hermanos, 1853).

${ }^{44}$ Quijano Otero, José María. Compendio de la Historia Patria: para el uso de las escuelas primarias (Bogotá: Imprenta de Medardo Rivas, 1874).
} 
A pesar de ser un héroe deshonrado, despreciado y olvidado por la historiografía que dio cuenta del éxito de la Independentista libertadora y la formación de la República de Colombia (1819-1830), C. García Rovira sigue estando presente en los monumentos locales, los imaginarios regionales y las representaciones nacionales. Ante los juicios y razones que cuestionan su inexperiencia bélica para enfrentar un ejército experimentado e invasor, cada generación historiográfica ha optado por explicar la causa de sus derrotas, embelleciendo su imagen como docto maestro, prócer abnegado y mártir vilipendiado ("El estudiante").

Existe así la continuidad analítica y documental empleada por las tres generaciones historiográficas comparadas, en contraste, con las variaciones y distorsiones anacrónicas que caracterizan el discurso histórico de las comunidades campesinas que coexisten en el teatro de operaciones de la batalla en el páramo de Cachirí, en 1816.

\section{Fuentes}

\section{Fuentes primarias}

\section{Archivo}

Real Academia de la Historia (RAH), España. Colección de don Pablo Morillo, conde de Cartagena, Madrid, Libro copiador de oficios despachados, núm. 19, folios 15-16.

\section{Libros (e impresos)}

Ancízar, Manuel. Peregrinación de Alpha (M. Ancizar) por las provincias del norte de la Nueva Granada, en 1850 i 1851. Bogotá: Imprenta de Echeverría hermanos, 1853.

Baralt, Rafael María y Díaz, Ramón. Resumen de la historia de Venezuela desde el año de 1797 hasta el de 1850. París: Imprenta de H. Fournier y compañía, 1841.

Baraya, José María. Biografias militares: o, historia militar del país en medio siglo. Bogotá: Imprenta de Gaitán, 1874.

Caballero, José María. Días de la independencia.... Bogotá: Biblioteca de Historia Nacional, 1902.

Colombia, Departamento de Antioquia. Estampilla conmemorativa del General Custodio García Rovira. Medellín: Litografía Arango, 1903.

Colombia, Documentos. 12 Cartas dirigidas al Ex-Jeneral Francisco de Paula Santander por los Cincuenta. Bogotá: Imprenta por José Avarza, 1837.

Colombia, Gobernación de Santander. Centenario de Custodio García Rovira en Bucaramanga, 1816 -8 de agosto- 1916. Bucaramanga: Taller Gráfico, 1916. 
La Batalla de Cachirí (1816). Representaciones históricas y monumentales sobre...

Escosura, Jerónimo de la. Biografía del teniente general Don Pablo Morillo.... Madrid: Real Academia de la Historia, 1840.

García Rovira, Custodio. “Comunicación dirigida a Andrés Rodríguez, secretario de Guerra del gobierno general de las Provincias Unidas de la Nueva Granada” [Cuartel general del Pie de la Cuesta, 13 de enero de 1816]. En Cacua Prada, Antonio, Custodio García Rovira. El estudiante mártir. Bogotá: Academia Colombiana de Historia, Plaza \&Janés, 1983.

Henao, Jesús y Arrubla, Gerardo. Historia de Colombia para la enseñanza secundaria, Tomo II. Bogotá: Librería Colombiana. Camacho Roldán \& Tamayo, 1920.

Quijano Otero, José María. Compendio de la Historia Patria: para el uso de las escuelas primarias. Bogotá: Imprenta de Medardo Rivas, 1874.

Restrepo, José Manuel. Historia de la revolución de la República de Colombia. Medellín: Bedout, 1974.

Santander, Francisco de Paula. Apuntamientos para las memorias sobre Colombia i la Nueva Granada. Bogotá, Imprenta de Lleras y Compañía, 1837.

Sevilla, Rafael. Memorias de un oficial del Ejército Español. Campañas contra Bolivar y los separatistas de América. Madrid: América, 1916.

\section{Fuentes Secundarias}

\section{Libros}

Balbo, Marcelo, Jordán, Ricardo y Simioni, Daniela (comps.). La ciudad inclusiva. Santiago de Chile: Cepal, 2003.

Brown, Matthew. Adventuring through Spanish Colonies: Simón Bolivar, Foreing Mercenaries and the Birth of New Nations. Liverpool: University of Liverpoool Press, 2006.

Cacua, Antonio. Custodio García Rovira. El Estudiante mártir. Bogotá: Plaza \& Janes, 1982.

Duque Muñoz, Lucía y Montoya Garay, Jhon Williams. Impactos territoriales en la transición de la Colonia a la Republica de la Nueva Granada. Bogotá: Universidad Nacional de Colombia, 2013.

Earle, Rebecca. Spain and the Independence of Colombia, 1810-1825. Chicago: University of Exeter Press, 1999.

Martínez, Armando. Disertación de la sesión ordinaria de la Academia de Historia de Santander: La batalla de Cachirí. Bucaramanga: Academia de Historia de Santander, 2 de febrero del 2016. 
Martínez, Armando. La batalla de Cachirí. El Socorro: Academia de Historia de Santander, 11 de febrero del 2016.

Martínez, Armando. La reconquista del centro del Nuevo Reino de Granada. Bucaramanga: Academia de Historia de Santander, 2016.

Nietzche, Federico. Sobre los beneficios y perjuicios de la historia para la vida (1874). Madrid: Gredos, 2009.

Pérez, Eduardo. Guerra irregular en la independencia de la Nueva Granada y Venezuela. Tunja: Universidad Pedagógica y Tecnológica, 1982.

Pérez, Luis. Los socorros de Nuestra Señora del Socorro, El Socorro y los socorranos a la independencia del centro-oriente de Colombia. Bogotá: Presidencia de la República, 2010.

Pérez, Luis. Narrativa, memoria y heroismo empresarial. Historia híbrida de la guerra, el conflicto y el empresariado de Santander (Colombia) desde mediados del siglo XIX. Bucaramanga: Ediciones UIS, 2015.

Perkowska, Magdalena. Historias híbridas. La nueva novela histórica latinoamericana (1985-2000) ante las teorías postmodernas de la historia. Madrid-España: Iberoamericana, 2008.

Rodríguez, Pedro. Significado histórico del nombre de algunas calles y carreras de la ciudad de Medellín. Medellín: Instituto Tecnológico Metropolitano, 2004.

Silva, Renán. A la Sombra de Clío: Diez ensayos sobre historia e historiografía. Bogotá: La carreta, 2007.

Villar, Pierre. Historia de España. Barcelona: Editorial Grijalbo, 1978.

\section{Capítulos de libros}

Pérez, Luis. "Emancipación política, resistencia ideológica y contra-hegemonía cultural en los discursos sobre la independencia. La condición "revolucionaria" del ser colombiano primigenio", en Pérez Pinzón, Luis Rubén (ed.), Historiar la muerte. II Representaciones sociopolíticas sobre el "buen morir por la patria" entre los revolucionarios de Colombia. Bucaramanga: Luis Rubén Pérez Pinzón, 2014

\section{Publicaciones en Internet}

Ocampo López, Javier. “Custodio García Rovira”, en Biografías Biblioteca virtual del Banco de la República, 2010, http://www.banrepcultural.org/blaavirtual/biografias/ garccusto.html. 